\title{
Proteomic analysis of potential immunoreactive proteins from muscle larvae and adult worms of Trichinella spiralis in experimentally infected pigs
}

\author{
Justyna Bien, Wladyslaw Cabaj and Bozena Moskwa
}

Witold Stefański Institute of Parasitology, Polish Academy of Sciences, Warsaw, Poland

\begin{abstract}
The present study was undertaken to identify potentially immunoreactive proteins of the muscle larvae (ML) and adult stage (Ad) of the nematode Trichinella spiralis Owen, 1835. To identify immunoreactive proteins that are specifically recognised by anti-Trichinella antibodies, ML and Ad crude extracts and their excretory-secretory (E-S) products were subjected to sodium dodecyl sulfate polyacrylamide gel electrophoresis (SDS-PAGE) and immunoblot with serum samples from pigs experimentally infected with T. spiralis. A total of 18 bands were selected for final identification by liquid chromatography-tandem mass spectrometry. To further understand the functions of the proteins identified in this study, gene ontology terms were applied. Results showed that the specific antibodies against $T$. spiralis reacted with protein bands matching heat shock proteins, aminopeptidase, enolase, isocitrate dehydrogenase NADP-dependent, tropomyosin, P49 antigen, serine proteinase, secreted 5'-nucleotidase, antigen targeted by protective antibodies, $53 \mathrm{kDa}$ E-S antigen, putative trypsin and paramyosin. Three proteins common for both adult stage and muscle larvae, including heat shock proteins, enolase and 5'-nucleotidase, might play important role during T. spiralis infection. These proteins are presumably presented to the host immune system and may induce humoral immune response. Thus, these proteins may be potential antigens for early diagnosis and the development of a vaccine against the parasite.
\end{abstract}

Keywords: Trichinella, antigens, mass spectrometry

Trichinella spiralis Owen, 1835 is an intracellular parasitic nematode of mammalian skeletal muscles. All lifestages of the parasite, including adult (Ad), newly- born larvae (NBL) and muscle larvae (ML) express a complex of proteins involved in host invasion, parasite survival and the generation of antibody responses in infected animals. Some of these proteins are suitable for immunodiagnosis and vaccine development.

During the last 10 years a number of papers concerning the identification of proteins of species of Trichinella (Owen, 1835 ) that might be useful for the development of a vaccine against parasite, a specific serological diagnostics, including species-specific diagnostics for detection of early infections, have been published (Bolas-Fernandez and Corral Bezara 2006, Wu et al. 2009, Zocevic et al. 2011, Bien et al. 2012).

Most studies have focused on the immunogenicity of ML proteins/antigens of $T$. spiralis because they are released and presented to the host immune system twice: by ingested larvae in the intestine, and again when the new generation of ML becomes resident in muscle cells. Thus, ML proteins are suggested to have a functional role in the induction of key immune responses both at the intestinal and muscle level that protects the host from subsequent infection with T. spiralis (see Appleton et al. 1991, BolasFernandez and Corral Bezara 2006).

ELISA and immunoblot are the most commonly used methods for the detection of anti-Trichinella antibodies. The use of excretory-secretory E-S ML antigens for early detection of infection with $T$. spiralis has not been useful, as in hosts which receive a low dose of $T$. spiralis the antibody response is delayed by several weeks. Gottstein et al. (2009) revealed that in swine infected with 100 or 500 T. spiralis ML, the ML specific antibodies were detected from 5-7 weeks post infection (wpi) and 4-5 wpi, respectively. Moreover, several studies have emphasised that E-S ML proteins contain components that can cross-react with sera from persons affected by other diseases including echinococcosis or cysticercosis and thus may not give reliable results in diagnostics (Jung et al. 2007, Gottstein et al. 2009).

Only a small number of reports are associated with NBL of $T$. spiralis or Ad antigens that stimulate strong immunity and are effective in protecting the host (Wang and Bell 1987a,b, Wang 1997, Salinas-Tobon et al. 2007).

Therefore, there is still a need to find such proteins produced by $T$. spiralis which may elicit an immune response in infected animals and human, and thus hold promise as

Address for correspondence: J. Bien; Witold Stefanski Institute of Parasitology, Polish Academy of Sciences, Twarda 51/55, Warsaw 00-818, Poland. Phone +48 2262062 26; Fax: +48 2262062 27; E-mail: jbien@twarda.pan.pl 
potential target proteins for specific early diagnostics and vaccine development.

1D immunoblot analysis combined with sequencing methodology, i.e. mass spectrometry, can be used to identify and characterise proteins of $T$. spiralis potentially reactive with specific antisera and can lead to the pinpointing of those proteins that are specific to each life stage of T. spiralis.

Our previous studies have focused on the analysis of the immune response of pigs against crude extracts of ML, Ad, NBL and E-S Ad and E-S ML after infection with 200 or 20000 T. spiralis ML (Bien at al. 2013). It has been shown that an antigen with a molecular weight of approximately $41 \mathrm{kDa}$, together with antigens localised between 20 and $27 \mathrm{kDa}$, as well as between 59 and $105 \mathrm{kDa}$, were produced by all of the examined life stages of $T$. spiralis, and were recognised by almost all experimentally infected pigs. These results indicated that $T$. spiralis produces some characteristic antigens throughout its development within the mammalian host. The identification of these proteins could be crucial for diagnostic studies.

The searching for antigens derived from new born larvae and adult worms recognised by pigs infected with $T$. spiralis for the early diagnosis and protection is a necessary step to control trichinellosis. Taking into account the fact that antifecundity effects and immunity to the NBL develops in T. spiralis-infected pigs and that very rapid gut expulsion does not occur in domestic swine (Murrell 1985, Marti and Murrell 1986), identification of immunogenic proteins characteristic for adult stage is important for diagnosis and protection. This confirms that immune responses at the gut level is important and perhaps responsible for much of the inhibition reflected as reduction in the establishment of muscle larvae.

The aim of present study was to identify the presence of antigenic proteins produced by muscle larvae and adult worms of $T$. spiralis, which are known to elicit an immune response in infected hosts and thus hold promise as potential target proteins for immunodiagnostics. The identification of these proteins in infected pigs will also help facilitate vaccine development. In this study, we integrated the 1D immunoblot analysis and mass spectrometry (MS) approaches.

\section{MATERIALS AND METHODS}

\section{Collection and preparation of proteins}

Adult worms and muscle larvae of Trichinella spiralis (strain ISS-003) were isolated and crude extracts (C) of Ad and ML (C Ad and $\mathrm{C} \mathrm{ML}$ ) as well as excretory-secretory proteins of $\mathrm{Ad}$ and ML (E-S Ad and E-S ML) were collected as described previously (Bien et al. 2013).

\section{SDS-PAGE and immunoblot}

Protein samples from E-S Ad, E-S ML, C Ad and C ML were diluted with loading buffer (Sigma-Aldrich Co., St. Louis, USA) up to a concentration of $10 \mu \mathrm{g} / \mathrm{lane}$, boiled for $5 \mathrm{~min}$ and centrifuged at $12000 \times \mathrm{g}$ at $4{ }^{\circ} \mathrm{C}$ for $10 \mathrm{~min}$. Proteins were separated by sodium dodecyl sulfate polyacrylamide gel electrophoresis
(SDS-PAGE) using 12\% acrylamide separating gels and 4\% acrylamide stacking gels in a Mini-PROTEAN Cell electrophoresis unit (Bio-Rad, Hercules, CA, USA) at $180 \mathrm{~V}$ for $60 \mathrm{~min}$. After electrophoresis, the gel was stained with silver. Immunoblot was used to verify which of the protein bands visible in SDS-PAGE react with specific antisera. For this purpose T. spiralis ML and Ad proteins were transferred onto nitrocellulose membranes for treatment with sera from pigs experimentally infected with T. spiralis. Based on immunoblot results published in a previous study (Bien et al. 2013), the early (15 dpi) and late (45 dpi) infection sera were used in the present study. The blots were cut into strips, which were then immunostained using serum from one pig experimentally infected with $200 \mathrm{ML}$ of $T$. spiralis. Strips with $\mathrm{C}$ Ad and E-S Ad proteins were incubated with serum taken at 15 days post infection (dpi), and strips with $\mathrm{C}$ ML and E-S ML proteins were incubated with serum taken at $45 \mathrm{dpi}$, according to previously experimental results (Bien et al. 2013). Serum sample taken at 0 dpi was used as negative control. Serum samples were diluted $1: 20$ and incubated for $1.5 \mathrm{~h}$ at room temperature (RT). Goat anti-pig IgG conjugated to horse-radish peroxidase (Bethyl Laboratories Inc., Montgomery, TX, USA) used as second antibody was diluted $1: 1500$, added to each strip and incubated for $1 \mathrm{~h}$ at RT. Bands were visualised with SIGMAFAST TM 3.3'-Diaminobenzidine (Sigma-Aldrich Co.). The reaction was stopped by washing the strips with distilled water (Bien et al. 2013).

\section{Proteomic analyses - mass spectrometric and protein identi- fication}

Mass spectrometric (MS) compatible silver staining was performed to visualise protein bands for identification. Immunoractive protein bands of interest were excised from the gel and analysed by liquid chromatography-tandem mass spectrometer (LC-MS/MS) in the Laboratory of Mass Spectrometry, Institute of Biochemistry and Biophysics, Polish Academy of Sciences (Warsaw, Poland). Samples were concentrated and desalted on a RPC18 pre-column (Waters Corporation, Milford, MA, USA), and further peptide separation was achieved on a nano-Ultra Performance Liquid Chromatography (UPLC) RP-C18 column (Waters, BEH130 C18 column, $75 \mu \mathrm{m}$ i.d., $250 \mathrm{~mm}$ long) of a nanoACQUITY UPLC system, using a 45 min linear acetonitrile gradient. The column outlet was directly coupled to the Electrospray ionisation ion source of the OrbitrapVelos type mass spectrometer (Thermo Fisher Scientific Inc., Waltham, MA, USA), working in the regime of data dependent MS to MS/MS switch. An electrospray voltage of $1.5 \mathrm{kV}$ was used. Raw data files were pre-processed with Mascot Distiller software (version 2.4.2.0, MatrixScience - http://www.matrixscience.com/search_form_select.html). The obtained peptide masses and fragmentation spectra were matched to the National Center for Biotechnology Information (NCBI) non-redundant database (31002772 sequences/10668937692 residues), with a Metazoe filter (3330924 sequences) using the Mascot search engine (Mascot Daemon v. 2.4.0, Mascot Server v. 2.4.1, MatrixScience). The following search parameters were applied: enzyme specificity was set to trypsin, peptide mass tolerance to $\pm 20 \mathrm{ppm}$ and fragment mass tolerance to $\pm 0.6 \mathrm{Da}$. The protein mass was left as unrestricted and mass values as monoisotopic with one missed cleavage being allowed. Alkylation of cysteine by carbamidomethylation as fixed and oxidation of methionine was set as a variable modification. 

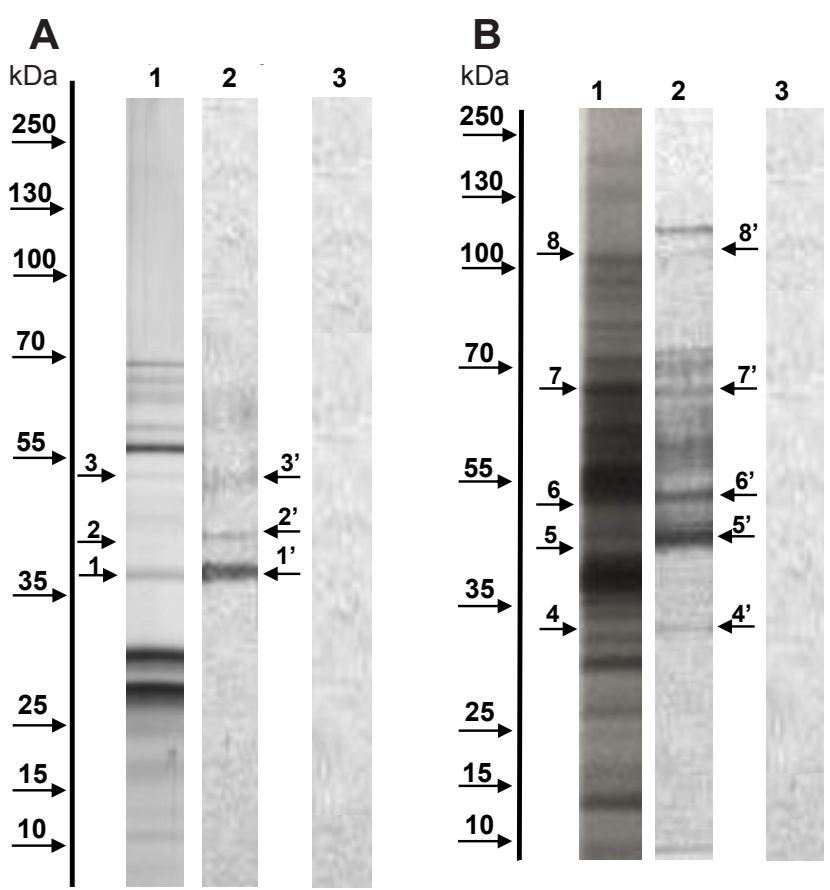

Fig. 1. Electrophoretic separation of the proteins of muscle larvae from Trichinella spiralis and immunoblot. A - representative overlay of silver-stained gel image of $T$. spiralis muscle larvae excretory-secretory (E-S ML) antigens (lane 1) and recognition pattern of $T$. spiralis E-S ML antigens (lane 2) by antibodies from $T$. spiralis-infected pigs, negative control (lane 3); B - representative overlay of silver-stained gel image of $T$. spiralis crude extract of muscle larvae antigens (C ML) (lane 1) and recognition pattern of $T$. spiralis $\mathrm{C}$ ML antigens (lane 2) by antibodies from T. spiralis-infected pigs, negative control (lane 3 ).

Protein identification was performed using the Mascot search engine (MatrixScience), with the probability based algorithm. The expected value threshold of 0.05 was used for analysis, which means that all peptide identifications had less than 1 in 20 chance of being a random match.

Gene ontology (GO) terms were applied to the identified proteins using UniProt (http://www.uniprot.org) (Magrane et al. 2011) and QuickGO (http://www.ebi.ac.uk/) databases (Huntley et al. 2009).

\section{RESULTS}

\section{Trichinella spiralis protein analysis by SDS-PAGE}

In an attempt to identify parasite antigens, proteins were resolved by SDS-PAGE and stained with silver. Electrophoretic profiles of E-S products of $T$. spiralis and $\mathrm{C} \mathrm{Ad}$ and ML are shown in Figs. 1, 2A,B, lane 1. Protein profiles of E-S ML and C ML antigens were present in the area between 10 and $100 \mathrm{kDa}$ (Fig. 1A,B, lane 1). Silver staining of E-S Ad and C Ad showed that the majority of specific bands are present in the area around 15 and $70 \mathrm{kDa}$ (Fig. 2A,B, lane 1).

\section{Immunoblot analysis of proteins of adults and muscle larvae of Trichinella spiralis}

The results of the immunoblot of ML and Ad proteins are shown in Figs. 1A,B, lane 2, 2A,B, lane 2, respectively.

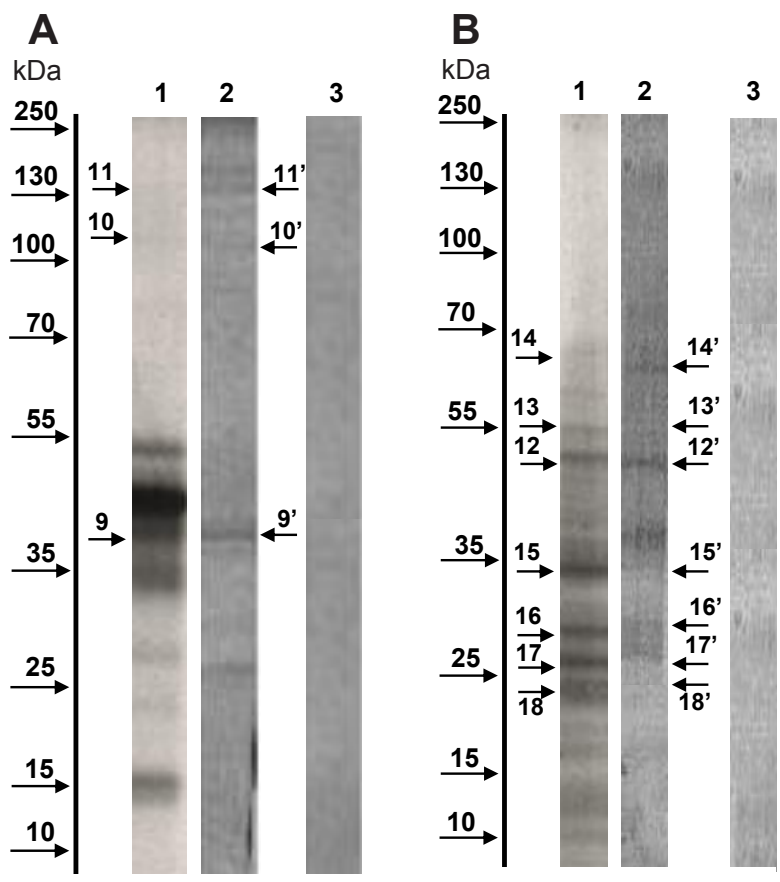

Fig. 2. Electrophoretic separation of the proteins of adult worms from Trichinella spiralis and immunoblot. A - representative overlay of silver-stained gel image of $T$. spiralis adult worm excretory-secretory (E-S Ad) antigens (lane 1) and recognition pattern of $T$. spiralis E-S Ad antigens (lane 2), negative control (lane 3); B - representative overlay of silver-stained gel image of T. spiralis crude extract of adult worm (C Ad) antigens (lane 1) and recognition pattern of $T$. spiralis $\mathrm{C} \mathrm{Ad}$ antigens (lane 2), negative control (lane 3). Numbered protein bands are listed in Table 1 . Bands marked as $1-18$ correspond to proteins identified on silver-stained gels (Figs. 1A and 2B, lane 1) while bands marked as 1'-18' correspond to immunoreactive bands identified by immunoblot (Figs. 1A and 2B, lane 2).

There were 8 bands (bands E-S ML 1'-3', bands C ML 4'-8') recognised by serum taken at 45 dpi (Fig. 1A,B, lane 2) and 10 bands (bands E-S Ad 9'-11'; bands C Ad 12'-18') displaying reactivity with sera taken at $15 \mathrm{dpi}$ (Fig. 2A,B, lane 2).

These protein bands (marked as 1'-18') were matched to the corresponding protein bands (marked as 1-18) in silver stained gels (Figs. 1A,B, 2A,B; lane 1). The named bands were selected for further analysis by MS. Lane 3 (Figs. 1A,B, 2A,B) represent negative control.

\section{Identification of proteins of Trichinella spiralis using mass spectrometry}

A total of 18 bands, named 1'-18' were selected from gels (bands 1-18) for the final identification by LC-MS/ MS (Figs. 1A,B, 2A,B). Searching the NCBI non-redundant database using the Mascot search engine with peptide masses and fragmentation spectra obtained by LC-MS/MS analysis identified the selected bands as proteins from species of Trichinella. From the aforementioned bands only 17 were successfully identified (Table 1, Fig. 3), several of the identified immunoreactive bands contained more than one protein. 
Table 1. Identification of proteins of Trichinella spiralis by liquid chromatography-tandem mass spectrometry.

\begin{tabular}{|c|c|c|c|c|c|c|c|}
\hline \multirow{2}{*}{ Group } & \multirow{2}{*}{ Band No. } & \multirow[b]{2}{*}{ Name of protein } & \multirow{2}{*}{$\begin{array}{l}\text { Access. no. closest } \\
\text { homologue/Strain }\end{array}$} & \multicolumn{2}{|c|}{ Theoretical $^{\mathrm{c}}$} & \multirow{2}{*}{$\begin{array}{l}{[\mathrm{ms}]_{\mathrm{d}}} \\
\text { score }\end{array}$} & \multirow{2}{*}{$\begin{array}{l}\text { No. } \\
\text { matched } \\
\text { peptides }\end{array}$} \\
\hline & & & & Mw & pI & & \\
\hline \multirow{4}{*}{$\begin{array}{l}\text { I } \\
\text { [excretory-secretory } \\
\text { proteins of muscle larvae] }\end{array}$} & $1[\mathrm{E}-\mathrm{S} \mathrm{ML}]$ & P49 antigen, partial & M64242.1 & 34.5 & 5.23 & 457 & 11 \\
\hline & $2[\mathrm{E}-\mathrm{S} \mathrm{ML}]$ & serine proteinase & AY028974.1 & 48.6 & 5.97 & 149 & 3 \\
\hline & & P49 antigen, partial & M64242.1 & 34.5 & 5.23 & 57 & 2 \\
\hline & 3 [E-S ML] & 5'-nucleotidase & XM_003374516.1 & 53.3 & 4.96 & 80 & 4 \\
\hline \multirow{9}{*}{$\begin{array}{l}\text { II } \\
\text { [proteins of muscle larvae] }\end{array}$} & $4[\mathrm{C} \mathrm{ML}]$ & antigen targeted by protective antibodies & U01847.1 & 31.7 & 4.76 & 137 & 4 \\
\hline & $5[\mathrm{C} \mathrm{ML}]$ & $53 \mathrm{kDa}$ excretory/secretory antigen & $\mathrm{U} 25127.1$ & 47.0 & 8.42 & 665 & 17 \\
\hline & & $53 \mathrm{kDa}$ excretory/secretory protein & DQ399911.1 & 46.7 & 7.98 & 265 & 6 \\
\hline & & serine protease & EU302800.1 & 35.7 & 5.97 & 434 & 7 \\
\hline & & enolase & AF363629.1 & 48.3 & 5.75 & 491 & 11 \\
\hline & $6[\mathrm{C} \mathrm{ML}]$ & 5'-nucleotidase & XM_003374516.1 & 53.3 & 4.96 & 54 & 2 \\
\hline & $7[\mathrm{C} \mathrm{ML}]$ & putative trypsin & XM_003381619.1 & 72.7 & 8.83 & 202 & 22 \\
\hline & & heat shock protein 70 & AY046874.2 & 68.7 & 5.06 & 125 & 3 \\
\hline & 8 [C ML] & paramyosin & XM_003371604.1 & 102.5 & 5.40 & 1000 & 27 \\
\hline \multirow{3}{*}{$\begin{array}{l}\text { III } \\
\text { [excretory-secretory } \\
\text { proteins of adult stage] }\end{array}$} & 9 [E-S Ad] & Tsp_09198 large tegumental protein & XM_003375570.1 & 42.5 & 8.9 & 44 & 3 \\
\hline & $10[\mathrm{E}-\mathrm{S} \mathrm{Ad}]$ & pancreatic alpha-amylase & XM_003376392.1 & 109.3 & 8.03 & 86 & 2 \\
\hline & 11 [E-S Ad] & $\mathrm{f}$ & - & - & - & - & - \\
\hline \multirow{11}{*}{$\begin{array}{l}\text { IV } \\
\text { [proteins of adult stage] }\end{array}$} & $12[\mathrm{C} \mathrm{Ad}]$ & 5'-nucleotidase & XM_003374516.1 & 53.3 & 4.96 & 131 & 5 \\
\hline & $13[\mathrm{C} \mathrm{Ad}]$ & heat shock protein 4 & XM_003376308.1 & 74.6 & 5.45 & 180 & 3 \\
\hline & & UDP-N-acetylglucosamine diphosphorylase & XM 003371898.1 & 62.7 & 5.73 & 124 & 2 \\
\hline & $14[\mathrm{C} \mathrm{Ad}]$ & heat shock protein 70 & $\overline{\mathrm{AY}} 046874.2$ & 68.7 & 5.06 & 1174 & 48 \\
\hline & & chaperone protein DnaK & XM_003378243.1 & 73.4 & 5.73 & 588 & 24 \\
\hline & 15 [C Ad] & ATP synthase F1, beta subunit & XM_003377041.1 & 58.2 & 5.11 & 475 & 15 \\
\hline & & aminopeptidase A/I & XM 003377655 & 55.4 & 6.2 & 199 & 6 \\
\hline & $16[\mathrm{C} \mathrm{Ad}]$ & enolase & AF363629.1 & 48.3 & 5.75 & 666 & 18 \\
\hline & $17[\mathrm{C} \mathrm{Ad}]$ & isocitrate dehydrogenase, NADP-dependent & XM_003380431.1 & 51.5 & 8.55 & 134 & 3 \\
\hline & & phosphoglycerate kinase & XM_003369173.1 & 59.9 & - & 193 & 5 \\
\hline & 18 [C Ad] & tropomyosin & FR694973.1 & 32.8 & 4.65 & 546 & 18 \\
\hline
\end{tabular}

a band numbers correspond to those in Figure $1 \mathrm{~A}, \mathrm{~B}$ and $2 \mathrm{~A}, \mathrm{~B} ;{ }^{\mathrm{b}}$ accession number of the closest homologue obtained from the NCBI database using the identified protein as the query sequence; ${ }^{\mathrm{c}}$ theoretical MW $(\mathrm{kDa})$ and pI values were obtained from MASCOT search results; ${ }^{\mathrm{d}}$ Mascot Mowse probability score $(\mathrm{p}<0.005) ;{ }^{\mathrm{e}}$ number of matched mass values; ${ }^{\mathrm{f}}$ protein could not be identified; E-S ML - excretory-secretory proteins of muscle larvae; $\mathrm{C} M L$ - crude extract of muscle larvae; E-S Ad - excretory-secretory proteins of adult stage; C Ad - crude extract of adult stage.

In the T. spiralis E-S ML protein pattern, immunoblot revealed three protein bands (Fig. 1A, lane 2, bands 1', 2', 3') recognised by serum at $45 \mathrm{dpi}$, which were matched to the P49 antigen, serine proteinase and 5'-nucleotidase. In the $T$. spiralis $\mathrm{C}$ ML protein pattern five bands were specifically recognised by the serum (Fig. 1B, lane 2 , bands 4'-8'). These reactive protein bands of $T$. spiralis $\mathrm{C} \mathrm{ML}$ were identified as antigen targeted by protective antibodies, $53 \mathrm{kDa}$ excretory/secretory antigen, serine protease, enolase, 5'-nucleotidase, putative trypsin, heat shock protein 70 (Hsp70) and paramyosin.

In the T. spiralis E-S Ad pattern the bands specifically recognised by serum at 15 dpi were identified as $T$. spiralis large tegumental protein and pancreatic alpha-amylase (Fig. 2A, lane 2, bands E-S Ad 9', 10'). Band 11', which was present in the E-S Ad T. spiralis protein pattern and was recognised by infective serum, was not positively identified by LC-MS/MS (Fig. 2A, lane 2). In the T. spiralis $\mathrm{C}$ Ad pattern the protein band 12' specifically recognised by infective serum (Fig. 2B, lane 2) was matched to the T. spiralis 5'-nucleotidase. Bands 13' and 14' contained more than one protein and were matched to the heat shock proteins (Hsp), and UDP-N-acetylglucosamine diphosphorylase and chaperone protein DnaK, respectively.

The specific antibodies against $T$. spiralis were found to react with protein bands (Fig. 2B, lane 2, bands C Ad 15', 16 ', 17', and 18') matching to the ATP synthase F1, aminopeptidase A/I, enolase, isocitrate dehydrogenase NADPdependent and tropomyosin.

\section{Functional categories of proteins from adult stage and muscle larvae of Trichinella spiralis by gene ontology}

Gene ontology signatures of 18 out of the 19 proteins identified were available. To further understand the functions of the proteins identified in this study, we queried against the UniProt database and those resultant proteins were classified into molecular function and biological process according to GO hierarchy using QuickGO (http://www.ebi.ac.uk/) (Figs. 3, 4A-D). For the molecular function ontology, 11 subcategories were assigned for adult stage proteins, of which the activities of binding and catalytic activity were the two major molecular function categories. Among the adult stage proteins most 


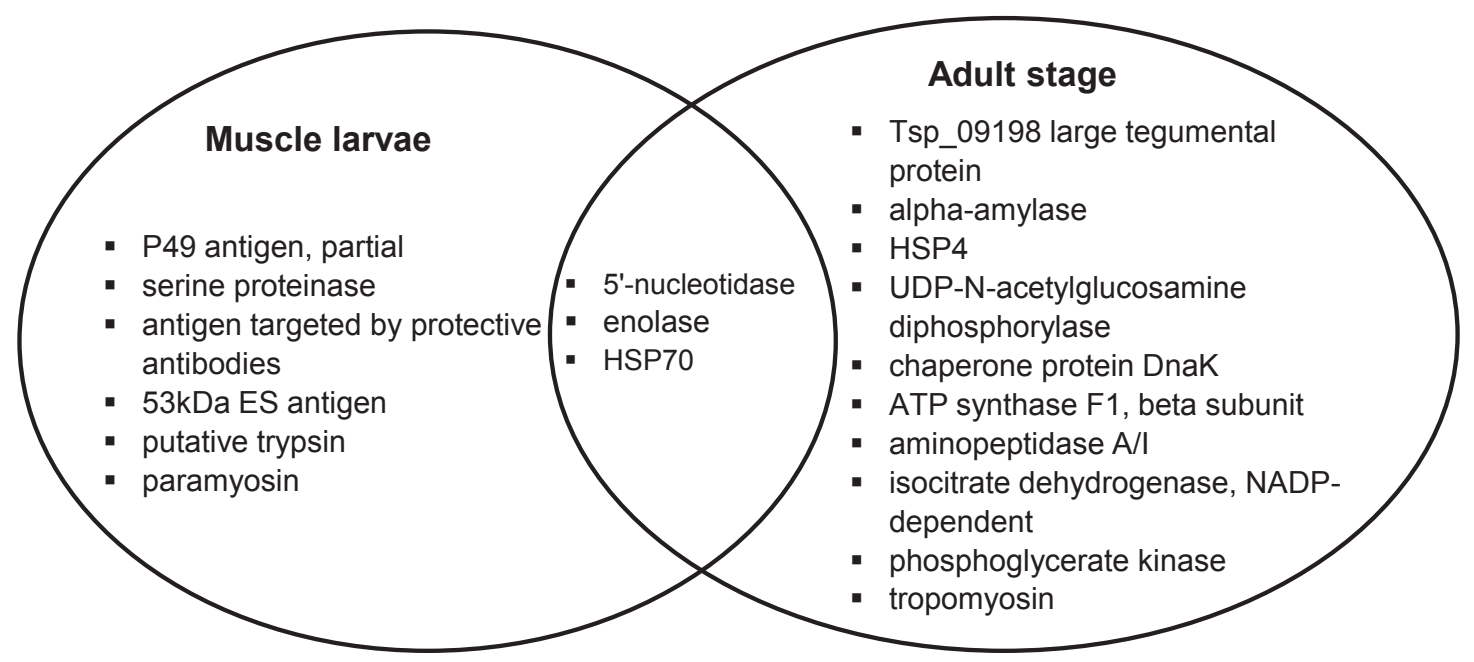

Fig. 3. Common and different proteins from muscle stages and adults of Trichinella spiralis.

\section{A Adult stage}

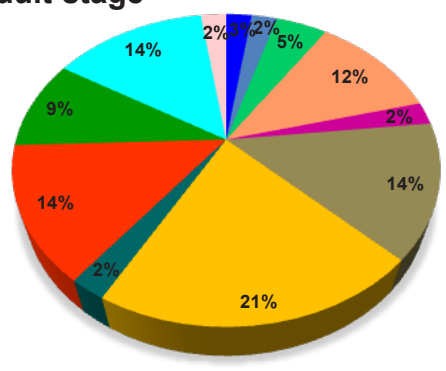

B Muscle larvae

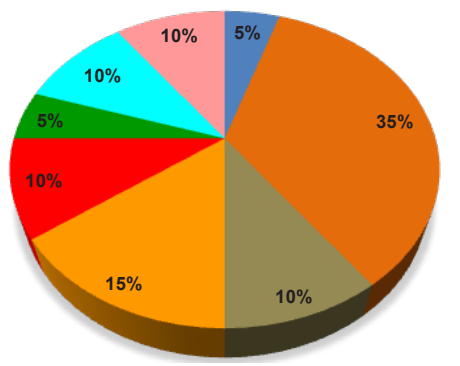

- isocitrate dehydrogenase activity - phosphopyruvate hydratase activity - transferase activity w hydrolase activity - transporter activity = small molecule binding =ion binding - NAD binding - organic cyclic compound binding - carbohydrate derivative binding w heterocyclic compound binding unknown

= phosphopyruvate hydratase activity = hydrolase activity = small molecule binding $=$ ion binding

- organic cyclic compound binding - carbohydrate derivative binding $=$ heterocyclic compound binding =unknown

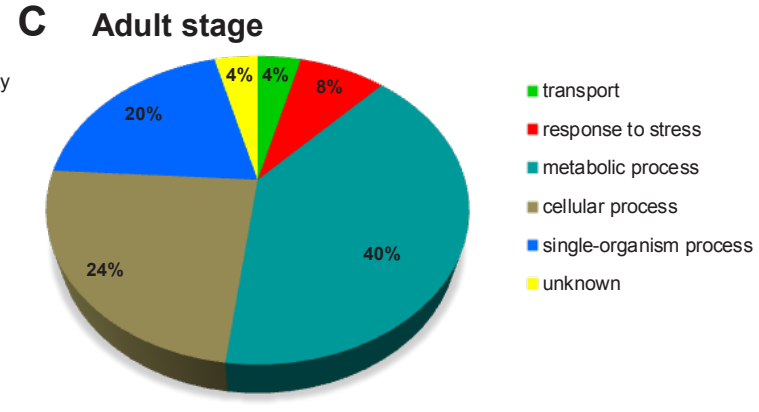

D Muscle larvae

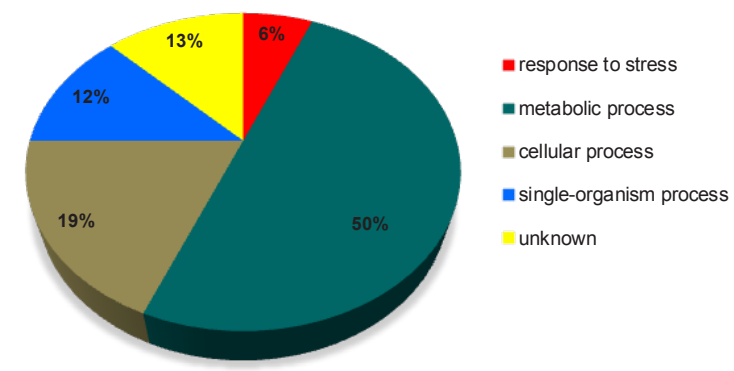

Fig. 4. Gene ontology categories of proteins of adult worms and muscle larvae of Trichinella spiralis. The identified proteins were classified into molecular function ( $\mathbf{A}$ - the adult stage proteins; $\mathbf{B}$ - muscle larvae proteins) and biological process $(\mathbf{C}-$ the adult stage proteins; D - muscle larvae proteins) by UniProt and QuickGO according to their gene oncology signatures.

of the assigned binding activity could be assigned to ion binding (GO:0043167, 9, 21\%), small molecule binding (GO:0036094, 6, 14\%), organic cyclic compound binding (GO:0097159, 6 14\%), heterocyclic compound binding (GO:1901363, 6, 14\%), carbohydrate derivative binding (GO:009736, 4, 9\%) and to NAD binding (GO:0051287, 1, $2 \%$ ). The proteins in the catalytic activity group also can be classified into subgroups based on the specific functions. The majority of proteins are related to hydrolase activity (GO:0016787, 5, 12\%), transferase activity (GO:0016740, 2, 5\%) and transporter activity (GO:0005215, 1, 2\%) (Fig. 4A).

For the molecular function ontology, the classification results showed that the muscle larvae proteins were divided into 7 subcategories. Most of the assigned molecular functions could be assigned to hydrolase activity (7, 35\%), ion binding $(3,15 \%)$, small molecule binding $(2,10 \%)$, heterocyclic compound binding $(2,10 \%)$ and organic cyclic compound binding (2, 10\%) (Fig. 4B).

In the category of biological process, a large part of adult stage of proteins of $T$. spiralis were related to metabolic process (GO:0008152, 10, 40\%), cellular process (GO:0009987, 6, 24\%) and single-organism process (GO:0044699, 5, 20\%). Less commonly, the proteins were involved in response to stress (GO:0006950, 2, 8\%) and transport (GO:0006810, 1, 4\%) (Fig. 4C). A significant part of muscle larvae proteins were classified to metabolic process $(8,50 \%)$, cellular process $(3,19 \%)$, singleorganism process $(2,12 \%)$ and response to stress $(1,6 \%)$ (Fig. 4D). 


\section{DISCUSSION}

Identification of proteins of Trichinella spiralis is very important in elucidating host-parasite interactions, and is a key factor which will help researchers in the development of immunological detection methods and vaccines to control infection with T. spiralis (Liu et al. 2013a, Zocevic et al. 2011, Bolas-Fernandez and Corral Bezara 2006, Wang and Bell 1987a). Application of classical immunoblot and proteomic techniques such as mass spectrometry are very useful in the identification of these proteins.

The present study was undertaken to identify proteins of T. spiralis with potential for early serological diagnosis of trichinellosis and effective vaccine. To meet this goal the SDS-PAGE analysis was conducted to estimate the size of proteins of muscle larvae and adult worms of T. spiralis. An immunoblot was used to verify which of these proteins react with anti-Trichinella antibodies.

In the present study, a total of 18 immunoreactive bands were selected from SDS-PAGE gels for final identification by LC-MS/MS. Of these, 17 protein bands were identified and represented 19 different proteins. Some of the identified immunoreactive bands contain more than one protein. In such situation we were looking for the proteins known from their immunogenic properties. Additionally, to further understand the functions of the $T$. spiralis proteins identified in this study, these proteins were categorised based on the GO annotation of biological process and molecular functions, which might be related i.e. to the invasion of host tissues and cells, larval migration or molting.

In patterns of proteins of $T$. spiralis (muscle larvae and adult worms), the specific antibodies against $T$. spiralis reacted with protein bands containing Hsp, aminopeptidase, enolase, isocitrate dehydrogenase NADP-dependent, tropomyosin, P49 antigen, serine proteinase, 5'-nucleotidase, antigen targeted by protective antibodies, $53 \mathrm{kDa} \mathrm{E}-\mathrm{S}$ antigen, putative trypsin, isocitrate dehydrogenase, NADPdependent, phosphoglycerate kinase and paramyosin (Table 1, Fig. 3). Three of these proteins were common for both of the developmental stages of T. spiralis: Hsp, enolase, and 5'-nucleotidase. In our study, three out of 17 immunoreactive bands were identified as containing Hsp, which play a role in protection of the parasite against stress or injury. Hsp are involved in tissue invasion, intracellular survival as well as in binding antigens and presenting them to the immune system (Vayssier et al. 1999, Martinez et al. 2000, Devaney 2006, Nishikawa et al. 2008, Kampinga and Craig 2010).

Many of the earlier published studies showed that these proteins are highly conserved among different species and highly immunogenic during infection caused by different of pathogens, i.e. Toxoplasma gondii (Nicolle et Manceaux, 1908), Leishmania donovani (Laveran et Mesnil, 1903), Scistosoma japonicum (Katsurada, 1904) (Kaur et al. 2011, He et al. 2010, Mohamed et al. 2003) including Trichinella (see Vayssier et al. 1999). Wang et al. (2009) showed that recombinant Hsp70 identified by immunoscreening an adult cDNA library is an immunogenic protein released by parasites and is exposed to the host immune system during infection, thus making it a possible candidate for further investigation as a vaccine antigen against infection with T. spiralis.

Hsp are critical factors for T. spiralis during the intestinal phase, especially Hsp70 is considered responsible for stability of transcriptional factors, which regulate gene expression and induce rapid moulting from ML to the Ad stage in the intestine (Vayssier et al. 1999, Wang et al. 2009, Zocevic et al. 2011).

It is worth noting that a highly reactive protein band of crude extract from muscle larvae of $T$. spiralis (band 7) has been identified as containing a Hsp 70. In our study Hsp proteins were detected only in the crude extracts of the parasite, although in the previously reported study by Ko and Fan (1996), Hsp proteins were documented in both crude extract and E-S products of infective-stage larvae of T. spiralis. Moreover, two of the protein bands (bands 13', 14 ') in the Ad crude extract that reacted with specific antisera were also identified as T. spiralis Hsp.

The 5'-nucleotidase is a nucleotide-metabolising enzyme that has been found in T. spiralis E-S ML protein patterns by several authors (Gounaris 2002, Robinson and Connolly 2005, Robinson et al. 2005, 2007). This enzyme is able to regulate the host immune and inflammatory responses by modulating nucleotide levels during infection (Gounaris 2002, Liu et al. 2013b).

Three protein bands including E-S ML products (band 3), C ML (band 6) and C Ad (band 12) represent the enzyme, 5'-nucleotidase. A previous study showed the presence of this protein in the E-S protein profile muscle larvae of T. spiralis and showed that 5'-nucleotidase was identified as a protein common to the E-S proteomes of T. spiralis and T. britovi (Pozio, la-Rosa, Murrell et Lichtenfels, 1992) (Robinson et al. 2005, Bien et al. 2012).

Enolase was first identified in crude extracts of muscle larvae but not in the E-S products (Nakada et al. 2005). Bernal et al. (2004) revealed that enolase, through the activation of plasminogen (a proenzyme of the serine protease plasmin), is involved in many processes including fibrinolysis and degradation of the extracellular matrix. Moreover, this enzyme may contribute to tissue migration during all developmental stages of T. spiralis (Nakada et al. 2005). Dea-Ayuela and Bolas-Fernandez (2005), using a combination of 2D- immunoblott and MS, confirmed the immunoreactive property of enolase. In our study, this enzyme has been found in protein bands selected from crude extracts of muscle larvae (band 5) and the adult stage (band 16).

In conclusion, adult worms and muscle larvae of T. spiralis produce proteins with antigenic properties, some of which were identified in other helminth species as potential targets for diagnostics and vaccine candidates. In addition, our results showed the presence of three proteins, common for both of the examined developmental stages, which may play an essential role during intestinal phase of infection. These antigens are presumably exposed to the host immune system, and may induce a humoral immune response making them potential antigens for development of an early diagnostic method and vaccine against parasite. 
Acknowledgements. This work was partially supported by W. Stefánski Institute of Parasitology of the Polish Academy of Sciences internal project to support for young scientists and by the Polish Ministry of Science and Higher Education grant No, NN303 344 935. We thank L.J. Norbury and D. Mlocicki for criti- cal advice. We are grateful to A.M. Morales (Department of Infectious, Parasitic and Immunomediated Diseases, Istituto Superiore di Sanita, Rome, Italy) and K. Nöckler (Federal Institute for Risk Assessment, Berlin, Germany) for providing experimentally Trichinella-infected sera.

\section{REFERENCES}

Appleton J.A., Bell R.G.M., Homan W, van Knapen F. 1991: Consensus on Trichinella spiralis antigens and antibody. Parasitol. Today. 7: 190-192.

Bernal D., de la Rubia J.E., Carrasco-Abda A.M., Toledo R., Mas-Coma S., Marcilla A. 2004: Identification of enolase as a plasminogen-binding protein in excretory-secretory products of Fasciola hepatica. FEBS Lett. 563: 203-206.

Bien J., Cabaj W., Moskwa B. 2013: Recognition of antigens of three different stages of the Trichinella spiralis by antibodies from pigs infected with T. spiralis. Exp. Parasitol. 134: 129-137.

Bien J., Näreaho A., Varmanen P., Gozdzik K., Moskwa B., Cabaj W., Nyman T.A., Savijoki K. 2012: Comparative analysis of excretory-secretory antigens of Trichinella spiralis and Trichinella britovi muscle larvae by two-dimensional difference gel electrophoresis and immunoblotting. Proteome Sci. 10: 10.

Bolas-Fernandez F., Corral Bezara L.D. 2006: TSL-1 antigens of Trichinella: an overview of their potential role in parasite invasion, survival and serodiagnosis of trichinellosis. Res. Vet. Sci. 81: 297-303.

Dea-Ayuela M.A., Bolas-Fernandez F. 2005: Two-dimensional electrophoresis and mass spectrometry for the identification of species-specific Trichinella antigens. Vet. Parasitol. 132: 43-49.

Devaney E. 2006: Thermoregulation in the life cycle of nematodes. Int. J. Parasitol. 36: 641-649.

Gottstein B., Pozio E., Nöckler K. 2009: Epidemiology, diagnosis, treatment, and control of trichinellosis. Clin. Microbiol. Rev. 22: $127-145$.

GounARIS K. 2002: Nucleotidase cascades are catalyzed by secreted proteins of the parasitic nematode Trichinella spiralis. Infect. Immun. 70: 4917-4924.

He S., Yang L., Lv Z., Hu W., Cao J., Wei J., Sun X., Yang J., ZHENG H., WU Z. 2010: Molecular and functional characterization of a mortalin-like protein from Schistosoma japonicum (SjMLP/hsp70) as a member of the HSP70 family. Parasitol. Res. 107: 955-966.

Huntley R.P., Binns D., Dimmer E., Barrell D., O’Donovan C., Apweiler R. 2009: QuickGO: a user tutorial for the webbased Gene Ontology browser. Database 2009: bap010.

Jung D., Teifke J.P., Karger A., Michael K., Venz S., Wittmann W., Kindermann K., Nöckler K., Mundt E. 2007: Evaluation of baculovirus-derived recombinant $53-\mathrm{kDa}$ protein of Trichinella spiralis for detection of Trichinella-specific antibodies in domestic pigs by ELISA. Parasitol. Res. 100: 429-437.

Kampinga H.H., Craig E.A. 2010: The HSP70 chaperone machinery: J proteins as drivers of functional specifity. Nat. Rev. Mol. Cell. Biol. 11: 579-592.

Kaur T., Sobti R.C., Kaur S. 2011: Cocktail of gp63 and Hsp70 induces protection against Leishmania donovani in BALB/c mice. Parasite Immunol. 33: 95-103.

Ko R.C., FAN L. 1996: Heat shock response of Trichinella spiralis and T. pseudospiralis. Parasitology 96: 89-95.

Liu P., Wu X.P., Bai X., Wang X.L., Yu L., Rosenthal B., Blaga R., Lacour S., Vallee I., Boireau P., Gherman C., Oltean M., Zhou X.N., Wang F., Zhao Y., Liu M.Y. 2013a: Screening of early antigen genes of adult-stage Trichinella spiralis using pig serum from different stages of early infection. Vet. Parasitol. 194: 222-225.

Liu R.D., Wang Z.Q., Wang L., Long S.R., Ren H.J., Cui J. 2013b: Analysis of differentially expressed genes of Trichinella spiralis larvae activated by bile and cultured with intestinal epithelial cells using real-time PCR. Parasitol. Res. 112: 4113-4120.
Magrane M., UniProt Consortium 2011: UniProt Knowledgebase: a hub of integrated protein data. Database, Article ID bar009.

Marti H.P., Murrell K.D. 1986: Trichinella spiralis: antifecundity and antinewborn larvae immunity in swine. Exp. Parasitol. 62: $370-375$.

Martinez J., Perez-Serrano J., Bernadina W.E., RodriguEZ-CAABeiro F. 2000: Detection of heat shock protein-70 from Trichinella spiralis larvae using a modification of the routine western blotting procedure. J. Parasitol. 86: 637-639.

Martínez-Abrajan D.M., Hernandez-Sanchez J. 2007: Trichinella spiralis: strong antibody response to a $49 \mathrm{kDa}$ newborn larva antigen in infected rats. Exp. Parasitol. 115: 60-167.

Mohamed R.M., Aosai F., Chen M., Mun H.S., Norose K., Belal U.S., PiaO L.X., Yano A. 2003: Induction of protective immunity by DNA vaccination with Toxoplasma gondii HSP70, HSP30 and SAG1 genes. Vaccine 21: 2852-2861.

MurRell K.D. 1985: Trichinella spiralis: acquired immunity in swine. Exp. Parasitol. 59: 347-354.

Nakada T., Nagano I., Wu Z., Takahashi Y. 2005: Molecular cloning and functional expression of enolase from Trichinella spiralis. Parasitol. Res. 96: 354-360.

Nishikawa M., Takemoto S., Takakura Y. 2008: Heat shock protein derivatives for delivery of antigens to antigen presenting cells. Int. J. Pharm. 354: 23-27.

Robinson M.W., Connolly B. 2005: Proteomic analysis of the excretory-secretory proteins of the Trichinella spiralis L1 larva, a nematode parasite of skeletal muscle. Proteomics 5: 4525-4532.

Robinson M.W., Gare D.C., Connolly B. 2005: Profiling excretory/secretory proteins of Trichinella spiralis muscle larvae by two dimensional gel electrophoresis and mass spectrometry. Vet. Parasitol. 132: 37-41.

Robinson M.W., Greig R., Beattie K.A., Lamont D.J., ConNOLLY B. 2007: Comparative analysis of the excretory-secretory proteome of the muscle larva of Trichinella pseudospiralis and Trichinella spiralis. Int. J. Parasitol. 37: 139-148.

Salinas-Tobon M.R., Navarrete-Leon A., Mendez-Loredo B.E., Esquivel-Aguirre D., Martínez-Abrajan D.M., HernandeZ-SANCHEZ J. 2007: Trichinella spiralis: strong antibody response to a $49 \mathrm{kDa}$ newborn larva antigen in infected rats. Exp. Parasitol. 115: 160-167.

Vayssier M., Le Guerhier F., Fabien J.F., Philippe H., Vallet C., Ortega-Pierres G., Soule C., Perret C., Liu M., Vega-Lopez M., Boireau P. 1999: Cloning and analysis of a Trichinella britovi gene encoding a cytoplasmic heat shock protein of $72 \mathrm{kDa}$. Parasitology 119: 81-93.

WANG C.H. 1997: Study of biological properties of Trichinella spiralis newborn larvae and the antiparasitic mucosal immunity of the host. Front. Biosci. 2: 317-330.

Wang C.H., Bell R.G. 1987a: Trichinella spiralis: host immunity against newborn larvae during a primary infection in rats. J. Parasitol. 73: 1069-1071.

Wang C.H., BeLl R.G. 1987b: Trichinella spiralis: intestinal expression of systemic stage-specific immunity to newborn larvae. Parasite Immunol. 9: 465-475.

Wang S., Zhu X., Yang Y., Yang J., Gu Y., Wei J., HaO R., Boireau P., CUI S. 2009: Molecular cloning and characterization of heat shock protein 70 from Trichinella spiralis. Acta Trop. 110: 46-51.

Wu X.P., Fu B.Q., Wang X.L., Yu L., Yu S.Y., Deng H.K., LiU X.Y., BoIREAU P., WANG F., LiU M.Y. 2009: Identification 
of antigenic genes in Trichinella spiralis by immunoscreening of cDNA libraries. Vet. Parasitol. 159: 272-275.

Zocevic A., Mace P., Vallee I., Blaga R., Liu M., Lacour

S.A., BoIreau P. 2011: Identification of Trichinella spiralis
Accepted 10 December 2014 early antigens at the pre-adult and adult stages. Parasitology 138: 463-471.

Cite this article as: Bien J., Cabaj W., Moskwa B. 2015: Proteomic analysis of potential immunoreactive proteins from muscle larvae and adult worms of Trichinella spiralis in experimentally infected pigs. Folia Parasitol. 62: 022. 